\title{
Interleukin-16 in tuberculous and malignant pleural effusions
}

\author{
X-J. Qin, H-Z. Shi, Z-X. Huang, L-F. Kang, W-N. Mo and C. Wu
}

\begin{abstract}
The aim of this study was to explore the presence of interleukin (IL)-16 in pleural effusions, the correlation between IL-16 levels and cytological parameters, as well as the chemoattractant activity of IL-16 on CD4+ T-lymphocytes.

Total nucleated cell and differential counts, and IL-16 concentrations in the pleural effusion from 32 patients with tuberculous pleurisy and $\mathbf{3 0}$ patients with lung cancer were determined. Threecolour flow cytometry was performed to determine T-lymphocyte subsets in cell pellets of pleural effusion. The chemoattractant activity of IL-16 for CD4+ T-lymphocytes was also analysed.

The levels of IL-16 were significantly higher in tuberculous than in malignant effusions. However, IL-16 levels could not be used for diagnostic purposes due to significant overlap between the two groups. Positive correlations were found between the IL-16 levels and CD4+ Tcells, and pleural fluid was chemotactic for CD4+ T-cells in vitro. Intrapleural administration of IL16 to patients produced a marked progressive influx of CD4+ T-cells into the pleural space.

Compared with malignant pleural effusion, interleukin-16 appeared to be increased in tuberculous pleural effusion. Interleukin-16 levels were positively related to the numbers of CD4+ T-cells, and interleukin-16 could directly induce CD4+ T-cell infiltration into the pleural space.
\end{abstract}

KEYWORDS: CD4+ T-cells, interleukin, pleural effusion

$\mathbf{T}$ he development of inflammatory processes in the pleural space may result in increased pleural vascular permeability, leading to the accumulation of fluid enriched in proteins and the recruitment of cells into the pleural space [1]. Although pleural effusion (PE) is common, very little information is available on the inflammatory and immune mechanisms that are involved in its development. In particular, it is unclear which cells and mediators are involved in the inflammatory processes, and whether resident immunocompetent cells may orchestrate the development of an inflammatory response. An accumulation of lymphocytes, especially helper T-lymphocytes, in PE frequently occurs in tuberculous pleurisy, and neoplastic effusions secondary to direct pleural involvement and/or metastases from malignancies [2, 3]. It has been reported that measurement of the proportion of CD4+ T-lymphocytes may be a useful clinical tool to select patients who are likely to have a poorer prognosis after surgery and who may be suitable for consideration of adjuvant treatments [4]. It is thought that the cytokines released from the accumulated lymphocytes may play some roles in the interaction between lymphocytes and tumour cells in malignant PE $[5,6]$. WONGTIM et al. [7] have demonstrated that the
PE concentration of interferon (IFN)- $\gamma$ is a good and useful diagnostic marker of tuberculosis presenting as a lymphocytic exudative PE. These findings suggest that lymphocytes and cytokines may play important roles in the development and the pathogenesis of PE.

The interleukin (IL)-16 protein, and its bioactivity, was initially identified in 1982 as a T-cell chemoattractant factor that was generated from mitogen- or antigen-stimulated human peripheral blood mononuclear cells [8,9]. IL-16 was one of the first cytokines to be characterised with chemoattractant activity for human T-cells and, therefore, was originally designated as lymphocyte chemoattractant factor. IL-16 can stimulate the synthesis of proinflammatory cytokines, including IL-1, IL-6 and tumour necrosis factor (TNF) $\alpha$ in monocytic cells [10]. IL-16 may play a role in various inflammatory diseases, such as allergic asthma [11, 12], rheumatoid arthritis [13], systemic lupus erythematosus [14] and AIDS [15]. Thus, this cytokine is postulated to be a proinflammatory and immunoregulatory molecule, playing an important role in the recruitment and activation of immune cells at the site of inflammation. To evaluate the presence and immunoregulatory role of IL-16 in PE, the
AFFILIATIONS

Dept of Respiratory and Critical Care Medicine, First Affiliated Hospital, Guangxi Medical University, Guangxi, People's Republic of China

CORRESPONDENCE

H-Z. Shi

Dept of Respiratory and Critical Care Medicine

First Affiliated Hospital

Guangxi Medical University

Nanning 530021

Guangxi

P.R. China

Fax: 867715359226

E-mail: hzshi@tom.com

Received

July 312004

Accepted after revision:

December 142004

SUPPORT STATEMENT

This study was supported in part by research grant No. 30260041 from the National Natural Science Foundation of China, foundation No. 200260 for the "Author of National Excellent Doctoral

Dissertation of P.R. China", and by research grant No. 0342031 from the Bureau of Science and Technology, Guangxi Zhuang Autonomous Zone, P.R. China. 
current authors examined the concentration of IL-16 in PE associated with tuberculosis and with lung cancer. Furthermore, the chemoattractant activity of IL-16 to induce CD4+ Tcell infiltration into the pleural space was also determined.

\section{MATERIALS AND METHODS Subjects}

The study protocol was approved by the institutional review board for human studies of the First Affiliated Hospital, Guangxi Medical University, Guangxi, P.R. China, and informed consent was obtained from all subjects. A total of 78 consecutive patients with PE of unknown causes were hospitalised for diagnostic investigation. The patients were subsequently included if the examinations of PE and/or biopsy specimens established a diagnosis of tuberculous or malignant PE. The patients were excluded if they had received any invasive procedures directed into the pleural cavity or if they had suffered chest trauma within 3 months prior to hospitalisation. Thirty-two patients (age range 22-76 yrs) were shown to have tuberculous PE, as evidenced by the growth of Mycobacterium tuberculosis from PE or by demonstration of granulomatous pleuritis on a closed pleural biopsy specimen in the absence of any evidence of other granulomatous diseases. After antituberculosis chemotherapy, the resolution of PE and clinical symptoms was observed in all patients with tuberculous pleurisy. Malignant PE was collected from 30 patients (age range 32-72 yrs) with newly diagnosed lung cancer. Histologically, all of these were adenocarcinomas. A diagnosis of malignant PE was established by the demonstration of malignant cells in pleural fluid and/or on a closed pleural biopsy specimen. At the time of sample collection, none of the patients had received any anticancer treatment, corticosteroids or other nonsteroid anti-inflammatory drugs.

\section{Sample collection and processing}

The PE samples were collected from each subject in heparintreated tubes, using a standard thoracocentesis technique within $24 \mathrm{~h}$ after hospitalisation. Venous blood $(10 \mathrm{~mL})$ was drawn simultaneously for obtaining sera. The PE specimens were immediately immersed in ice and were then centrifuged at $1,200 \times g$ for $5 \mathrm{~min}$. The cell-free supernatants of PE and sera were immediately frozen at $-70^{\circ} \mathrm{C}$ after centrifugation, to allow the determination of the concentrations of IL-16, lactate dehydrogenase and protein later. Analyses of PE for total nucleated cell and differentials counts were performed. A pleural biopsy was performed after the collection of PE.

\section{Flow cytometry}

Three-colour flow cytometry was performed to determine T-lymphocyte subsets in cell pellets of PE. The monoclonal antibodies (mAbs) used were anti-CD3-allophycocyanin (UCHT1), anti-CD4-fluorescein isothiocyanate (RPA-T4) and anti-CD8-Cy-chrome (RPA-T8). Appropriate isotype controls were performed for each experiment. All mAbs and controls were purchased from BD PharMingen (San Diego, CA, USA). Briefly, cells were incubated in the dark at room temperature for $30 \mathrm{~min}$, washed once in fluorescence-activated cell sorter buffer (calcium/magnesium-free Hanks' balanced salt solution (HBSS) containing $1 \mathrm{mg} \cdot \mathrm{mL}^{-1}$ bovine serum albumin and $0.1 \mathrm{mg} \cdot \mathrm{mL}^{-1}$ sodium azide), and fixed with $2 \%$ formaldehyde. Flow cytometry was performed on a Coulter Epics XL-MCL flow cytometer using System II software (Beckman Coulter Company, Miami, FL, USA).

\section{Measurement of IL-16}

The concentration of IL-16 in PEs and sera was measured by a sandwich enzyme-linked immunosorbent assay kit according to the manufacturer's protocol ( $\mathrm{R} \& \mathrm{D}$ Systems Inc., Minneapolis, MN, USA). All samples were assayed in duplicate.

\section{CD4+ T-cell chemotaxis assay}

Lymphocyte-enriched fractions were obtained from the peripheral blood of healthy adults by Ficoll-Hypaque gradient centrifugation (Pharmacia, Uppsala, Sweden). Untouched CD4+ T-cells were isolated by the depletion of non-CD4+ Tcells, i.e. CD8+ T-cells, B-cells, natural killer cells, dendritic cells, monocytes, granulocytes and erythroid cells, using the CD4+ T-Cell Isolation Kit II (Miltenyi Biotec, Auburn, CA, USA). All magnetic separation procedures were carried out according to the protocols provided by the manufacturer. CD4+ cell migration was assessed with a modification of the Boyden chamber assay, using a microchemotaxis chamber (Costar; Neuro Probe Inc., Cabin John, MD, USA). CD4+ cells $\left(1.0 \times 10^{6} \cdot \mathrm{mL}^{-1}\right.$ in RPMI 1640) were loaded into the upper well of the chamber, and $30 \mu \mathrm{L}$ of PE from five tuberculous and five cancer patients was placed in the bottom chamber. The two wells were separated by a polycarbonate filter paper with a pore size of $8 \mu \mathrm{m}$, and the chamber was incubated at $37^{\circ} \mathrm{C}$ for $3 \mathrm{~h}$. At the end of incubation, the filter was fixed, stained and mounted on a glass microscope slide. Migration was assessed by counting the number of cells that had migrated beyond a certain depth into the filter $(50 \mu \mathrm{m})$. To correct for donor-todonor variation, migration data of test samples were compared with their corresponding control values (HBSS alone) and expressed as the percentages above the control value. To demonstrate that IL-16 was responsible for CD4+ cell migration, blocking experiments were performed by mixing the PE with $5 \mu \mathrm{g} \cdot \mathrm{mL}^{-1}$ of anti-IL-16 mAb (clone 14.1) or IgG2a irrelevant isotype control (BD Pharmingen).

\section{Effects of intrapleural injected IL-16 on CD4+ T-cell recruitment}

A total of 12 patients with PE were included in this section of study, six of them were tuberculous patients and the remaining six were patients with lung cancer. Immediately after the collection of PE samples, $10 \mu \mathrm{g}$ of recombinant human IL-16 (R \& D Systems Inc.) in vehicle ( $0.1 \%$ human serum albumin in $0.9 \%$ saline) was injected into the pleural space of six patients, and vehicle only was injected into the pleural space of the other six patients. Intrapleural injection of IL-16 or vehicle was randomised. The dose of IL-16 was based upon a preliminary study involving two PE patients. PE collection for determining CD4+ T-cell numbers by flow cytometry were repeated 6,12 , 24 and $48 \mathrm{~h}$ after the injection of IL-16 or vehicle.

\section{Statistical analysis}

Data were expressed as mean \pm SEM. Changes of IL-16 in PE were adjusted to that in serum by calculating either the IL16 concentration ratio between PE and serum (PE/serum IL-16 ratio) or the difference between the concentrations of IL-16 between the two media (PE-serum IL-16 4 ). Nonparametric 
tests were used to analyse PE variables as these variables were not normally distributed. Comparisons of the data between different groups were performed using a Mann-Whitney U-test or Kruskal-Wallis one-way ANOVA on ranks. For IL-16 levels in $\mathrm{PE}$ and in corresponding serum, paired data comparisons were made using a Wilcoxon signed-rank test. The effects of intrapleural injected IL-16 or vehicle on CD4+ T-cell recruitment were compared through one-way repeated-measures ANOVA. The correlations between variables were determined by Spearman rank correlation coefficients. A p-value $<0.05$ was considered as statistically significant.

\section{RESULTS}

\section{Cytological characteristics in pleural effusion}

Cytological characteristics in PEs are illustrated in table 1. Subjects with tuberculosis showed a marked elevation of total cell counts, and a large proportion of these cells were lymphocytes, with some neutrophils and macrophages. Subjects with cancer had a large proportion of lymphocytes and macrophages in the pleural space. Importantly, on cytological examination, malignant cells were found in 13 subjects. Absolute lymphocyte counts displayed the highest values in tuberculous $\mathrm{PE}$, showing a significant increase in comparison with absolute lymphocyte counts in malignant PE $(p<0.001$; table 2$)$. Evaluation of the lymphocyte subsets in PE showed that T-cells, especially CD4+ T-cells, were dominant in all situations. More specifically, a significant rise of CD4+ Tcells and a significant decrease of CD8+ T-cells were observed in tuberculous PE in comparison with malignant PE (table 2).

\section{IL-16 concentrations in pleural effusion}

Table 3 shows the IL-16 levels in both PE and serum, by considering either the whole population or aetiological category separately. For the whole population, the mean IL-16 level was significantly higher in PE than in serum with an average $\mathrm{PE} /$ serum IL-16 ratio of $4.6 \pm 0.4$ and a mean PE-serum IL-16 $\Delta$ of $1,192.5 \pm 133.7 \mathrm{ng} \cdot \mathrm{L}^{-1}$. An important point

\begin{tabular}{|c|c|c|c|}
\hline \multirow[t]{2}{*}{ TABLE 1} & \multirow[b]{2}{*}{ Tuberculous PE } & \multirow[b]{2}{*}{ Malignant PE } & \multirow[b]{2}{*}{ p-values ${ }^{\#}$} \\
\hline & & & \\
\hline Subjects $n$ & 32 & 30 & \\
\hline Protein $\mathbf{g} \cdot \mathrm{L}^{-1}$ & $40.5 \pm 0.28$ & $36.9 \pm 0.28$ & 0.278 \\
\hline $\begin{array}{l}\text { Lactate dehydrogenase } \\
\text { IU } \cdot \mathrm{L}^{-1}\end{array}$ & $554.5 \pm 95.3$ & $786.0 \pm 152.1$ & 0.386 \\
\hline $\begin{array}{l}\text { Total cell counts } \\
\times 10^{9} \cdot \mathrm{L}^{-1}\end{array}$ & $2.39 \pm 0.13$ & $1.46 \pm 0.08$ & $<0.001$ \\
\hline \multicolumn{4}{|l|}{ Differential cell counts $\%$} \\
\hline Lymphocyte & $73.1 \pm 1.2$ & $46.8 \pm 1.2$ & $<0.001$ \\
\hline Neutrophil & $12.6 \pm 0.8$ & $3.8 \pm .06$ & $<0.001$ \\
\hline Macrophage & $12.9 \pm 0.8$ & $38.3 \pm 1.7$ & $<0.001$ \\
\hline Mesothelial cell & $1.7 \pm 0.2$ & $6.8 \pm 0.7$ & $<0.001$ \\
\hline Malignant cell & & $4.3 \pm 1.0$ & \\
\hline
\end{tabular}

Data are presented as mean $\pm \mathrm{SEM}$, unless otherwise stated. \#: the comparison between tuberculous and malignant groups was performed using the MannWhitney U-test.

\begin{tabular}{|c|c|c|c|c|}
\hline \multirow[t]{2}{*}{ TABLE 2} & \multicolumn{4}{|c|}{$\begin{array}{l}\text { Lymphocyte subpopulations in tuberculous and } \\
\text { malignant pleural effusion (PE) }\end{array}$} \\
\hline & & Tuberculous PE & Malignant PE & p-values $\#$ \\
\hline \multicolumn{2}{|c|}{ Subjects $n$} & 15 & 15 & \\
\hline \multicolumn{2}{|c|}{ Lymphocytes $\times 10^{9} \cdot \mathrm{L}^{-1}$} & $1.74 \pm 0.57$ & $0.67 \pm 0.23$ & $<0.001$ \\
\hline \multicolumn{2}{|c|}{ CD3+ \% } & $85.1 \pm 1.2$ & $85.6 \pm 1.3$ & 0.902 \\
\hline \multicolumn{2}{|l|}{ CD3+CD4+ \% } & $64.3 \pm 1.5$ & $54.8 \pm 1.7$ & 0.001 \\
\hline \multicolumn{2}{|c|}{$\mathrm{CD} 3+\mathrm{CD} 8+\%$} & $21.0 \pm 1.3$ & $30.5 \pm 1.3$ & $<0.001$ \\
\hline \multicolumn{2}{|c|}{ CD4+/CD8+ ratio } & $3.1 \pm 0.2$ & $1.8 \pm 0.1$ & $<0.001$ \\
\hline
\end{tabular}

Data are presented as mean \pm SEM, unless otherwise stated. \#: the comparison between tuberculous and malignant groups was performed using the MannWhitney U-test.

to note is that IL-16 in PE was nearly systematically in excess of that in serum on an individual basis, also since, in a total of 62 patients, only two had a IL-16 level in PE lower than that in serum, and both patients were in the malignant group. As shown in figure 1 , the concentration of IL-16 in PE of the tuberculous group $\left(2,118.1 \pm 227.0 \mathrm{ng} \cdot \mathrm{L}^{-1} ; 95 \%\right.$ confidence interval (CI) 1,655.2-2,581.1 $\left.\mathrm{ng} \cdot \mathrm{L}^{-1}\right)$ was significantly higher than that in the malignant group $\left(1,068.7 \pm 101.3 \mathrm{ng} \cdot \mathrm{L}^{-1} ; 95 \% \mathrm{CI}\right.$ $\left.861.5-1,275.9 \mathrm{ng} \cdot \mathrm{L}^{-1} ; \mathrm{p}<0.001\right)$. Similarly, the concentration of IL-16 in the sera of the tuberculous group $\left(515.7 \pm 46.5 \mathrm{ng} \cdot \mathrm{L}^{-1}\right.$; $95 \%$ CI $420.8-610.6 \mathrm{ng} \cdot \mathrm{L}^{-1}$ ) was also higher than that in the malignant group $\left(358.8 \pm 33.2 \mathrm{ng} \cdot \mathrm{L}^{-1} ; 95 \%\right.$ CI $289.8-$ $\left.425.7 \mathrm{ng} \cdot \mathrm{L}^{-1} ; \mathrm{p}=0.027\right)$. The difference of the PE-serum IL-16 $\Delta$ was much greater in tuberculous PE than in malignant PE $(p=0.001)$, but not for the PE/serum IL-16 ratio $(p=0.170$; table 3$)$. As illustrated in figure 2, IL-16 concentrations in PE were correlated with those in serum $(n=62 ; r=0.460 ; p<0.001)$.

\section{Correlation between pleural effusion IL-16 levels and cytological parameters}

The PE IL-16 level was positively correlated with total cell counts $(n=62 ; r=0.463 ; p<0.001)$, lymphocytes $(n=62 ; r=0.526$; $\mathrm{p}<0.001), \mathrm{CD} 3+$ T-cells $(\mathrm{n}=30 ; \mathrm{r}=0.638 ; \mathrm{p}<0.001), \mathrm{CD} 4+\mathrm{T}$-cells $(\mathrm{n}=30 ; \mathrm{r}=0.701 ; \mathrm{p}<0.001)$ and CD8+ T-cells $(\mathrm{n}=30 ; \mathrm{r}=0.382 ;$ $\mathrm{p}=0.037)$, but not with neutrophils $(\mathrm{n}=62 ; \mathrm{r}=0.344 ; \mathrm{p}=0.066)$, macrophages $(n=62 ; r=-0.126 ; p=0.327)$, mesothelial cells $(\mathrm{n}=62 ; \mathrm{r}=-0.199 ; \mathrm{p}=0.120)$ and malignant cells $(\mathrm{n}=13$; $\mathrm{r}=0.403 ; \mathrm{p}=0.172$; figs 3 and 4 ). The PE IL-16 level correlated best with numbers of CD4+ T-cells. Although the correlation between IL-16 level and CD8+ T-cell numbers reached statistical significance, the $r$-value was quite low $(r=0.383)$. These data provided indirect evidence that PE IL-16 might by produced by lymphocytes, especially CD4+ T-cells, or, alternatively, IL-16 might recruit CD4+ T-cells to infiltrate into PE.

\section{Pleural effusion was chemotactic for CD4+ cells}

The finding that the concentration of PE IL-16 correlated best with the number of CD4+ T-cells prompted the current authors to test the chemoattractant activity of PE on human peripheral CD4+ T-cells. The present results showed that PE from both tuberculous and malignant groups exerted a potent chemoattractant activity for CD4+ T-cells, and the chemoattractant activity of tuberculous PE was significantly greater than the 


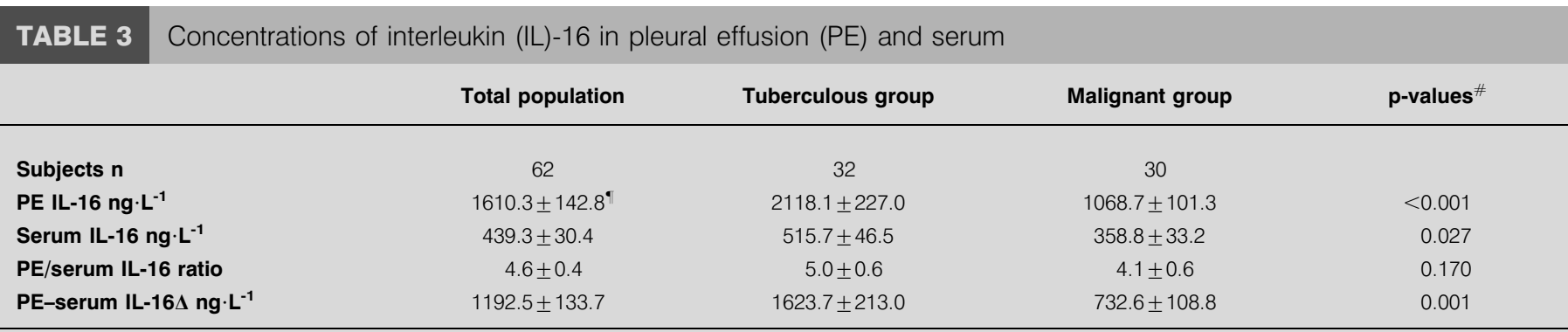

Data are presented as mean \pm SEM, unless otherwise stated. \#: comparison between tuberculous and malignant groups was performed using the Mann-Whitney U-test; ${ }^{\circ}$ compared with serum IL-16, $p<0.001$ determined by Wilcoxon signed-rank test.

activity exerted by malignant PE (fig. 5). To determine whether IL-16 was responsible for the recruitment of CD4+ T-cells, the ability of an anti-IL-16 mAb to neutralise the chemoattraction of CD4+ T-cells was tested. The anti-IL-16 mAb significantly suppressed CD4+ T-cell chemotaxis in both PE groups (fig. 5). These data provided indirect evidence that IL-16 was capable of inducing CD4+ T-cell recruitment into the pleural space.

\section{Recruitment of CD4+ T-cells into pleural effusion caused by IL-16}

To investigate the direct chemoattractant capacity of IL-16 to recruit CD4+ T-cells, human recombinant IL-16 was injected into the pleural space of patients with $\mathrm{PE}$, and the changes in CD4+ T-cell numbers were then observed using flow cytometry. Compared with the baseline value $\left(0.78 \pm 0.18 \times 10^{9} \cdot \mathrm{L}^{-1}\right.$; $95 \%$ CI $\left.0.33-1.24 \times 10^{9} \cdot \mathrm{L}^{-1}\right)$, no significant increase in the number of CD4+ T-cells could be seen $6 \mathrm{~h}\left(0.87 \pm 0.21 \times 10^{9} \cdot \mathrm{L}^{-1}\right.$; $95 \%$ CI $\left.0.34-1.40 \times 10^{9} \cdot \mathrm{L}^{-1} ; \mathrm{p}=0.130\right)$ after intrapleural IL-16 injection. The number of CD4+ T-cells increased with time, reaching statistical significance at $12 \mathrm{~h}\left(1.1 \pm 0.18 \times 10^{9} \cdot \mathrm{L}^{-1}\right.$; $95 \%$ CI $\left.0.62-1.56 \times 10^{9} \cdot \mathrm{L}^{-1} ; \mathrm{p}=0.001\right)$, and reaching a maximum at $24 \mathrm{~h}\left(1.90 \pm 0.46 \times 10^{9} \cdot \mathrm{L}^{-1} ; 95 \%\right.$ CI $0.74-3.08 \times 10^{9} \cdot \mathrm{L}^{-1}$; $\mathrm{p}=0.010)$; this significant CD4+ T-cell infiltration lasted $\geqslant 48 \mathrm{~h} \quad\left(1.73 \pm 0.35 \times 10^{9} \cdot \mathrm{L}^{-1} ; 95 \%\right.$ CI $0.84-2.63 \times 10^{9} \cdot \mathrm{L}^{-1}$; $\mathrm{p}=0.003$; fig. 6). After vehicle only was injected into the

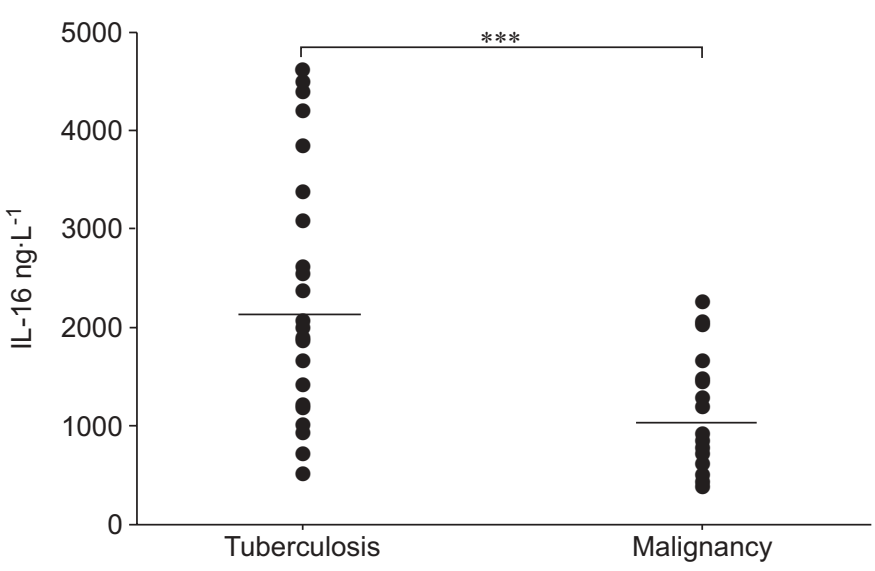

FIGURE 1. Comparison of concentrations of interleukin (IL)-16 in tuberculous and malignant pleural effusions. Horizontal bars represent means. Statistical analysis was performed using the Mann-Whitney U-test. ***: $p<0.001$ pleural cavity, no increases of CD4+ T-cell counts in PE obtained at four time points were observed when compared with the baseline measurement before injection (all $\mathrm{p}>0.05$ ).

\section{DISCUSSION}

During the first steps in the development of inflammatory processes, the migration and activation of leukocytes within the pleural space may be the effects of soluble mediators (eicosanoids, vasoactive amines and cytokines) released by "resident" cells that are activated by various stimuli [16]. IL-16 is synthesised by several kinds of cells [17]; caspase-3 enzymatically cleaves pro-IL-16 to a mature form of IL-16, which is biologically active as a multimer [18, 19]. Mature IL-16 exerts CD4-dependent and -independent effects [17]. The present study was conducted to determine the concentrations of IL-16 in PE, as well as the contribution of IL-16 to CD4+ T-cell recruitment into the pleural space. It has been shown that IL-16 concentrations were greater in PE from patients with tuberculosis than in PE from patients with malignancy. The current findings further provided direct evidence that IL-16 is capable of inducing CD4+ T-cell infiltration into the pleural space.

The cell origins of PE IL-16 were not identified in the present study. The primary aim of this study was to explore the presence of IL-16 in PE, as well as the chemoattractant activity

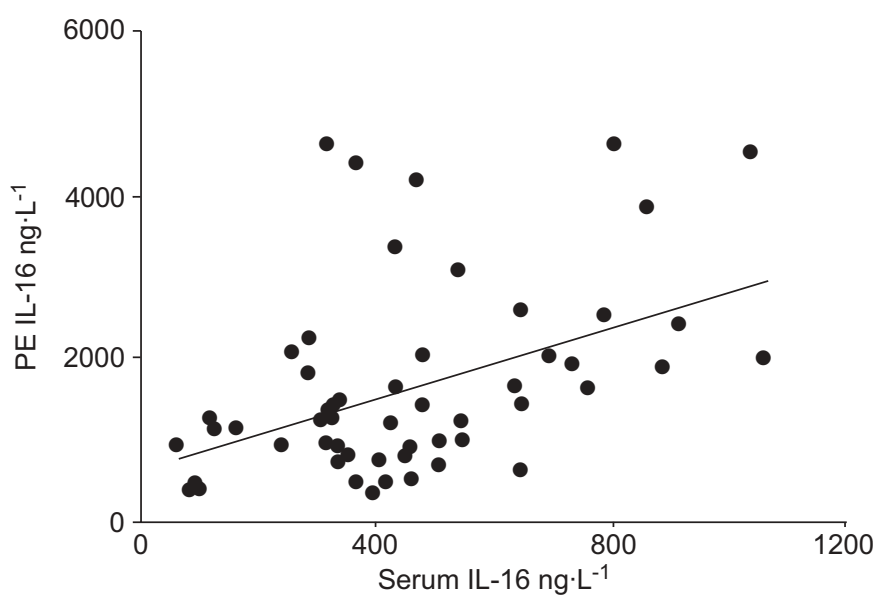

FIGURE 2. Correlations between interleukin (IL)-16 levels in pleural effusion $(\mathrm{PE})$ and serum, determined by Spearman rank correlation coefficients $(r=0.460$; $p<0.001)$. 

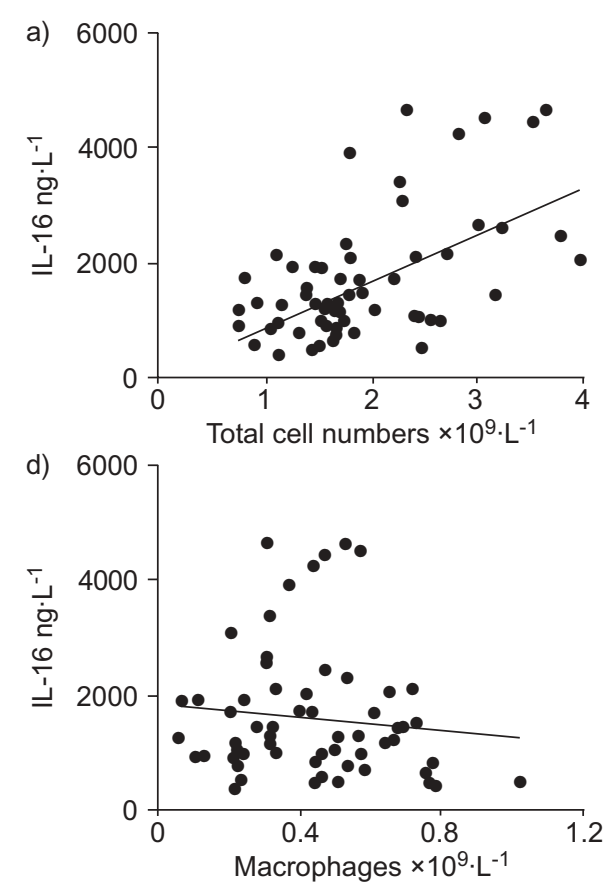
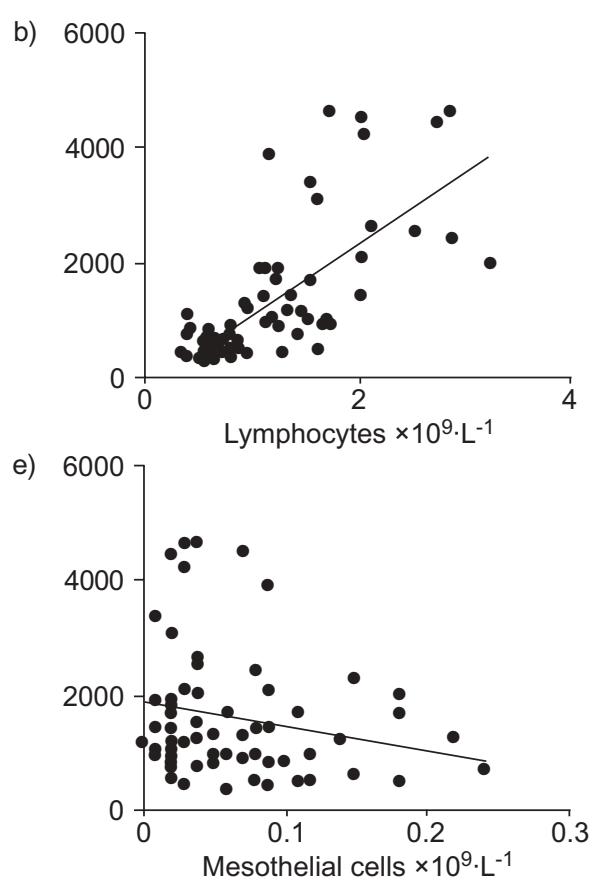
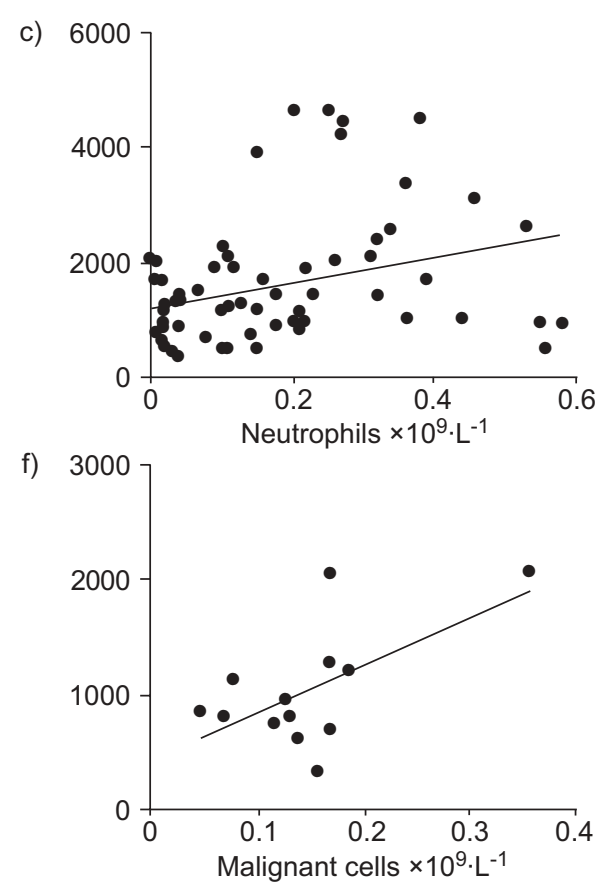

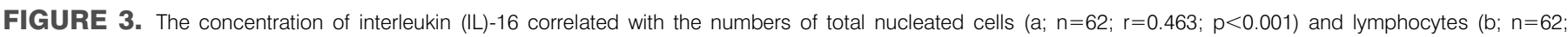

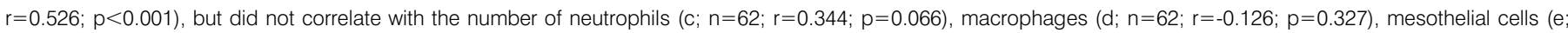

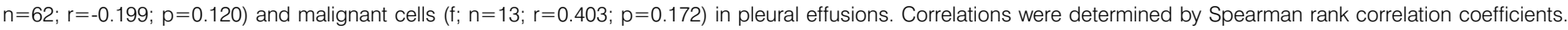

of PE IL-16 on CD4+ T-cells. It has been reported that IL-16 is synthesised by CD4+ T-cells [20], CD8+ T-cells [21], eosinophils [22], mast cells [23], dendritic cells [24], epithelial cells [11, 25] and fibroblasts [26]. The most interesting finding in the current study was that the concentration of IL-16 in PE is in excess of that in serum with an average PE/serum IL-16 ratio of 4.6 and a mean PE-serum IL-16 16 of $1,192.5 \mathrm{ng} \cdot \mathrm{L}^{-1}$, pointing to an additional source other than exudation from serum. The concentration of IL-16, as well as the values of PE-serum IL-16 $\Delta$, was significantly greater in tuberculous PE than in malignant PE. These findings suggested that more pleural sources of IL-16 exist in tuberculous patients. Local production has been reported for some cytokines, such as IL-8 [27], IFN- $\gamma$ $[7,28]$ and TNF- $\alpha[29]$, in inflammatory or neoplastic pleural disorders. Similarly, PE IL-16 can also be produced by inflammatory cells recruited into the pleural space. The PE IL-16 level was positively correlated with lymphocytes, CD4+ T-cells and CD8+ T-cells, suggesting that IL-16 might be produced by lymphocytes, especially CD4+ T-cells. The amount of IL-16 present in PE and deriving from recruited cells in PE might reasonably be well estimated by the PE-serum IL-16A, which takes into account the total IL-16 level in PE and the amount originating from plasma by diffusion. As expected, the PE-serum IL-16 $\Delta$ was positive for the PE samples in almost all of the studied patients except for two cancer patients. It should be noted that, although IL-16 levels in tuberculous PE were higher than those in malignant $\mathrm{PE}$, it is not possible to differentiate tuberculosis from

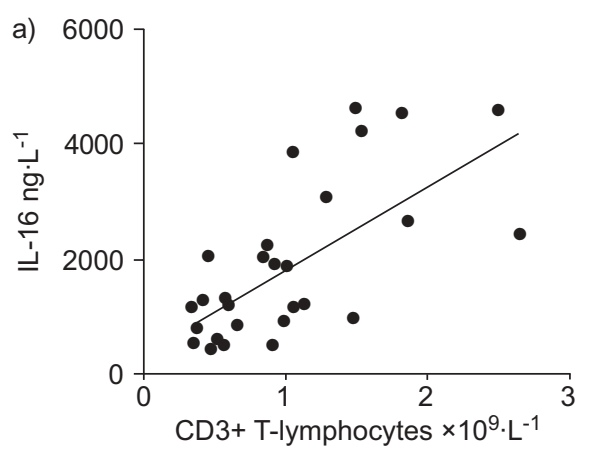

b)

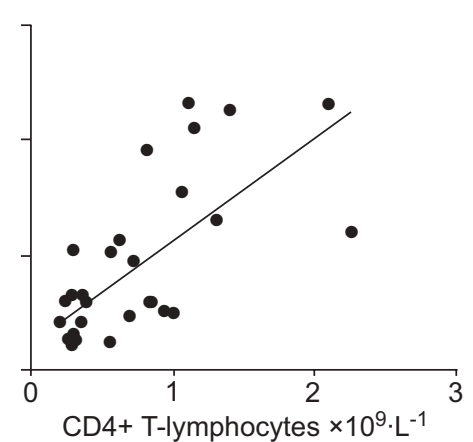

c)

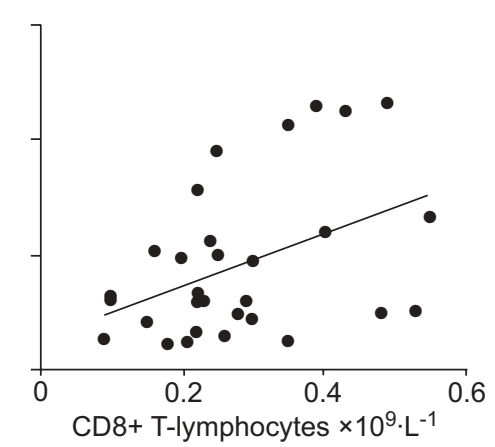

FIGURE 4. The concentration of interleukin (IL)-16 correlated with the numbers of CD3+ T-cells $(a ; r=0.638 ; p<0.001), C D 4+T-c e l l s(b ; r=0.701 ; p<0.001)$ and CD8+ $T$ cells $(c ; r=0.383 ; p=0.037$ ) in pleural effusions from 15 patients with tuberculous pleurisy and 15 patients with lung cancer. Correlations were determined by Spearman rank correlation coefficients. 


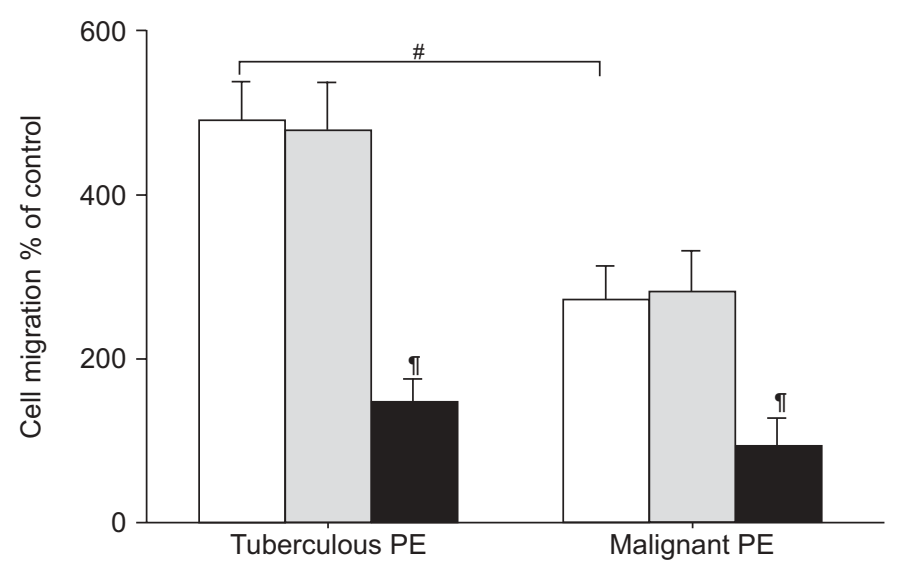

FIGURE 5. Pleural effusion (PE) is chemotactic for CD4+ T-cells. PEs from patients with tuberculous pleurisy $(n=5)$ and with lung cancer $(n=5)$ were used to stimulate chemotaxis of peripheral blood CD4+ T-cells isolated from healthy adults. $\square$ : chemotaxis in the absence of anti-interleukin (IL)-16 monoclonal antibody (mAb); 11: an irrelevant isotype control; $\mathbf{a}$ : chemotaxis in the presence of anti-IL-16 mAb. The comparison between tuberculous PE versus malignant PE was performed using the Mann-Whitney U-test. \#: $p<0.01 ; \because: p<0.01$ compared with the corresponding group without anti-IL-16 mAb, determined by Kruskal-Wallis oneway ANOVA on ranks.

malignant diseases due to the wide distribution and obvious overlap of IL-16 concentrations between the two groups.

Compared with peripheral blood, tuberculous PEs are enriched with CD4+ T-cells [2, 30]. Malignant pleuritis is frequently observed in lung cancer $[1,31]$, and patients with malignant pleuritis have a poor prognosis. In malignant PE, CD4+ cells are also dominant, and the proportion of CD8+ cells is significantly lower than that of CD4+ cells [32, 33]. In contrast, the proportion of CD4+ cells in the pleural cavity of lung cancer patients without malignant effusion is significantly

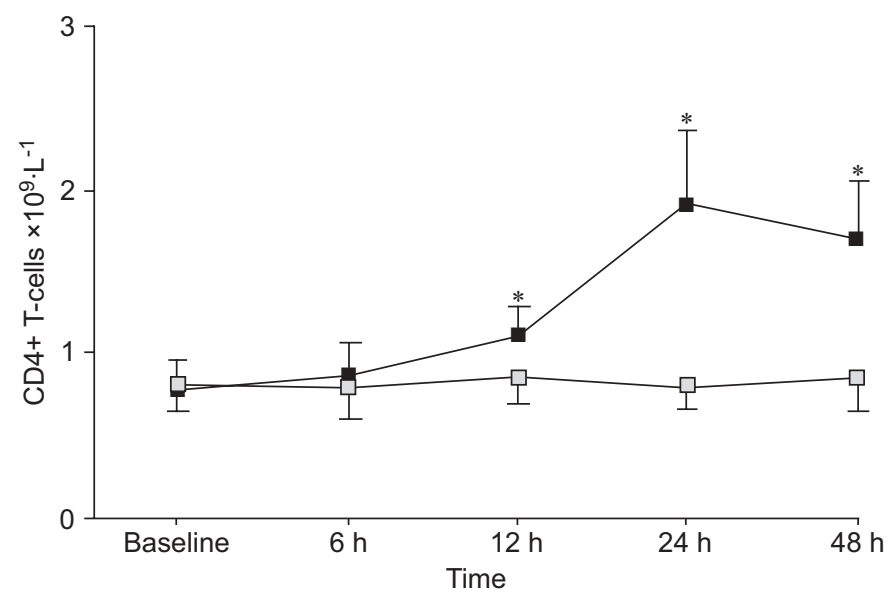

FIGURE 6. Changes of CD4+ T-cell numbers in pleural effusion from patients with tuberculous pleurisy and lung cancer, who were intrapleurally injected with vehicle $(\square)$ and recombinant human interleukin-16 (Ш). Data are presented as mean \pm SEM. $n=6$ for each group. ${ }^{*}: p<0.05$ for comparison of within-group change from baseline measurements determined by one-way repeated-measures ANOVA. lower than that of CD8+ cells [34]. However, the mechanism by which CD4+ T-cells infiltrate into pleural cavity is unknown so far. In the present study, the authors were prompted to evaluate whether pleural IL-16 might be responsible for the influx of CD4+ T-cells into the pleural space. The findings that the level of PE IL-16 correlated best with the numbers of CD4+ T-cells, and that an anti-IL-16 mAb inhibited the ability of the $\mathrm{PE}$ to stimulate peripheral CD4+ T-cell chemotaxis in vitro, suggested that IL-16 plays a role in the influx of CD4+ T-cells into the inflamed pleural space. Another important finding in the current study was that the intrapleural administration of human recombinant IL-16, not vehicle, of patients with PE produced a marked progressive influx of CD4+ T-cells into the pleural space when studied using flow cytometry. The changes were time-course related, in that the response was most marked at $24 \mathrm{~h}$ and could last $\geqslant 48 \mathrm{~h}$. The present results demonstrated that an intrapleural injection of $10 \mu \mathrm{g}$ IL-16 in patients with PE was able to chemoattract CD4+ T cells to be recruited into the pleural space.

In conclusion, compared with malignant pleural effusion, interleukin-16 appeared to be increased in tuberculous pleural effusion. The pleural effusion interleukin-16 concentrations were positively related to the numbers of CD4+ T-cells, and interleukin-16 could directly induce CD4+ T-cell infiltration into pleural effusion.

\section{REFERENCES}

1 Light RW. Clinical practice. Pleural effusion. N Engl J Med 2002; 346: 1971-1977.

2 Barnes PF, Mistry SD, Cooper CL, Pirmez C, Rea TH, Modlin RL. Compartmentalization of a CD4+ T lymphocyte subpopulation in tuberculous pleuritis. I Immunol 1989; 142: 1114-1119.

3 Chen YM, Yang WK, Whang-Peng J, Kuo BI, Perng RP. Elevation of interleukin-10 levels in malignant pleural effusion. Chest 1996; 110: 433-436.

4 Takahashi K, Saito S, Kamamura Y, Katakawa M, Monden Y. Prognostic value of CD4+ lymphocytes in pleural cavity of patients with non-small cell lung cancer. Thorax 2001; 56: 639-642.

5 Weissler JC, Nicod LP, Toews GB. Pulmonary natural killer cell activity is reduced in patients with bronchogenic carcinoma. Am Rev Respir Dis 1987; 135: 1353-1357.

6 Blanchard DK, Kavanagh JJ, Sinkovics JG, Cavanagh D, Hewitt SM, Djeu JY. Infiltration of interleukin-2-inducible killer cells in ascitic fluid and pleural effusions of advanced cancer patients. Cancer Res 1988; 48: 6321-6327.

7 Wongtim S, Silachamroon U, Ruxrungtham K, et al. Interferon gamma for diagnosing tuberculous pleural effusions. Thorax 1999; 54: 921-924.

8 Center DM, Cruikshank W. Modulation of lymphocyte migration by human lymphokines. I. Identification and characterization of chemoattractant activity for lymphocytes from mitogen-stimulated mononuclear cells. J Immunol 1982; 128: 2563-2568.

9 Cruikshank W, Center DM. Modulation of lymphocyte migration by human lymphokines. II. Purification of a lymphotactic factor (LCF). J Immunol 1982; 128: 2569-2574. 
10 Mathy NL, Bannert N, Norley SG, Kurth R. Cutting edge: CD4 is not required for the functional activity of IL-16. J Immunol 2000; 164: 4429-4432.

11 Laberge $S$, Ernst $P$, Ghaffar $O$, et al. Increased expression of interleukin-16 in bronchial mucosa of subjects with atopic asthma. Am J Respir Cell Mol Biol 1997; 17: 193-202.

12 Hessel EM, Cruikshank WW, Van Ark I, et al. Involvement of IL-16 in the induction of airway hyper-responsiveness and up-regulation of $\operatorname{IgE}$ in a murine model of allergic asthma. J Immunol 1998; 160: 2998-3005.

13 Klimiuk PA, Goronzy JJ, Weyand CM. IL-16 as an antiinflammatory cytokine in rheumatoid synovitis. J Immunol 1999; 162: 4293-4299.

14 Lee S, Kaneko H, Sekigawa I, Tokano Y, Takasaki Y, Hashimoto H. Circulating interleukin-16 in systemic lupus erythematosus. Br J Rheumatol 1998; 37: 1334-1337.

15 Zhou P, Devadas K, Tewari D, Jegorow A, Notkins AL. Processing, secretion, and anti-HIV-1 activity of IL-16 with or without a signal peptide in CD4+ T cells. J Immunol 1999; 163: 906-912.

16 Kroegel C, Antony VB. Immunobiology of pleural inflammation: potential implications for pathogenesis, diagnosis and therapy. Eur Respir J 1997; 10: 2411-2418.

17 Cruikshank WW, Kornfeld H, Center DM. Interleukin-16. J Leukoc Biol 2000; 67: 757-766.

18 Zhang Y, Center DM, Wu DM, et al. Processing and activation of pro-interleukin-16 by caspase-3. J Biol Chem 1998; 273: 1144-1149.

19 Baier M, Bannert N, Werner A, Lang K, Kurth R. Molecular cloning, sequence, expression, and processing of the interleukin 16 precursor. Proc Natl Acad Sci USA 1997; 94: 5273-5277.

$20 \mathrm{Wu}$ DM, Zhang Y, Parada NA, et al. Processing and release of IL-16 from CD4+ but not CD8+ T cells is activation dependent. J Immunol 1999; 162: 1287-1293.

21 Laberge S, Cruikshank WW, Beer DJ, Center DM. Secretion of IL-16 (lymphocyte chemoattractant factor) from serotonin-stimulated CD8+ $\mathrm{T}$ cells in vitro. I Immunol 1996; 156: 310-315.

22 Lim KG, Wan HC, Bozza PT, et al. Human eosinophils elaborate the lymphocyte chemoattractants. IL-16 (lymphocyte chemoattractant factor) and RANTES. J Immunol 1996; 156: 2566-2570.
23 Rumsaeng V, Cruikshank WW, Foster B, et al. Human mast cells produce the CD4+ T lymphocyte chemoattractant factor, IL-16. J Immunol 1997; 159: 2904-2910.

24 Kaser A, Dunzendorfer S, Offner FA, et al. A role for IL-16 in the cross-talk between dendritic cells and $\mathrm{T}$ cells. J Immunol 1999; 163: 3232-3238.

25 Bellini A, Yoshimura H, Vittori E, Marini M, Mattoli S. Bronchial epithelial cells of patients with asthma release chemoattractant factors for T lymphocytes. J Allergy Clin Immunol 1993; 92: 412-424.

26 Sciaky D, Brazer W, Center DM, Cruikshank WW, Smith TJ. Cultured human fibroblasts express constitutive IL-16 mRNA: cytokine induction of active IL-16 protein synthesis through a caspase-3-dependent mechanism. J Immunol 2000; 164: 3806-3814.

27 Pace E, Gjomarkaj M, Melis M, et al. Interleukin-8 induces lymphocyte chemotaxis into the pleural space. Role of pleural macrophages. Am J Respir Crit Care Med 1999; 159: 1592-1599.

28 Shimokata K, Kishimoto H, Takagi E, Tsunekawa $H$. Determination of the T-cell subset producing gammainterferon in tuberculous pleural effusion. Microbiol Immunol 1986; 30: 353-361.

29 Hua CC, Chang LC, Chen YC, Chang SC. Proinflammatory cytokines and fibrinolytic enzymes in tuberculous and malignant pleural effusions. Chest 1999; 116: 1292-1296.

30 Fujiwara H, Tsuyuguchi I. Frequency of tuberculin-reactive T-lymphocytes in pleural fluid and blood from patients with tuberculous pleurisy. Chest 1986; 89: 530-532.

31 Hausher F, Yabro JW. Diagnosis and treatment of malignant pleural effusion. Semin Oncol 1985; 12: 54-75.

32 Lucivero G, Pierucci G, Bonomo L. Lymphocyte subsets in peripheral blood and pleural fluid. Eur Respir J 1988; 1: 337-340.

33 Albera C, Mabritto I, Ghio P, Scagliotti GV, Pozzi E. Lymphocyte subpopulations analysis in pleural fluid and peripheral blood in patients with lymphocytic pleural effusions. Respiration 1991; 58: 65-71.

34 Takahashi K, Sone S, Kimura S, Ogura T, Monden Y. Phenotypes and lymphokine-activated killer activity of pleural cavity lymphocytes of lung cancer patients without malignant effusion. Chest 1993; 103: 1732-1738. 